NUBIA CAROLINA MANCHOLA VARON

\title{
METABOLISMO DOS AMINOÁCIDOS RAMIFICADOS \\ E SUA PARTICIPAÇÃO NA MODULAÇÃO DA \\ DIFERENCIAÇÃO EM Trypanosoma cruzi
}

Tese apresentada ao programa de PósGraduação em Biología da Relação Patógeno-Hospedeiro do Instituto de Ciências Biomédicas da Universidade de São Paulo, para a obtenção do Título de Doutor em Ciências.

Área de concentração: Biología da Relação Patógeno-Hospedeiro

Orientador: Prof. Dr. Ariel M. Silber

Versão corrigida. A versão eletrônica, encontra-se disponível tanto na Biblioteca do ICB quanto na Biblioteca Digital de Teses e Dissertações da USP ( BDTD).

São Paulo

2017 


\section{RESUMO}

MANCHOLA, N. C. Metabolismo dos aminoácidos ramificados e sua participação na modulação da diferenciação em Trypanosoma cruzi. 2017. 156 f. Tese (Doutorado em Parasitologia) - Instituto de Ciências Biomédicas, Universidade de São Paulo, São Paulo 2017.

A doença de Chagas é uma doença negligenciada com aproximadamente 8 milhões de pessoas cronicamente infectadas e mais de 17 milhões sob risco de infecção. Atualmente as duas drogas disponíveis para o tratamento da doença são limitadas em relação à eficácia e apresentam problemas como a baixa tolerância dos pacientes devido a sua toxicidade, o que evidencia a necessidade urgente de identificar novos alvos terapêuticos visando o desenvolvimento de drogas eficazes para o tratamento da doença. Vários estudos têm descrito a importância dos aminoácidos no ciclo de vida do $T$. cruzi, que além de atuarem na síntese proteica e no metabolismo energético, estão relacionados a diferentes funções no parasito. Apesar de estudos anteriores indicarem os aminoácidos de cadeia ramificada (BCAA - leucina, isoleucina e valina) como integrantes do metabolismo em $T$. cruzi é curioso o fato de ainda haver poucos estudos na literatura sobre a identificação de funções relevantes dos BCAA para a biologia do parasita, em forma individual ou bem associados a outros aminoácidos. Esse projeto teve o propósito de: (1) Avaliar o papel biológico que os BCAA tem ao longo do ciclo de vida do parasita, com especial enfase nos processos de diferenciação, (2) Caracterizar o primeiro passo metabólico dos BCAA em T. cruzi: a sua tomada do méio extracelular. (3) Identificar as enzimas responsáveis pela desaminação dos BCAA e caracteriza-las cinéticamente. (4) Avaliar o papel funcional do complexo enzimático desidrogenase de alfa-cetoácidos ramificados $(B C A K D H)$. (5) Estudar a expressão e localização intracelular do $B C A K D H$ nas formas do parasita. (6) Investigar a funcionalidade do $B C A K D H$ e as suas proteinas constituintes.

Palavaras-chave: Trypanosma cruzi. Aminoácidos. Leucina. Valina. Isoleucina. Doençã de Chagas. Diferenciação. Metaciclogênesis. Transporte. 


\begin{abstract}
MANCHOLA, N. C. Branched chain amino acids metabolism and their participation in the diferentiation modulation of Trypanosoma cruzi. 2017. 156 p. Ph.D. Thesis (Parasitology) Instituto de Ciências Biomédicas, Universidade de São Paulo, São Paulo 2017.

Chagas disease is a neglected disease with approximately 8 million people chronically infected and more than 40 million at risk of infection. Currently the two drugs available for the treatment of the disease are limited in relation to efficacy and have serious problems such as the low tolerance of patients due to their high toxicity. These facts highlights the urgent need for the identification of new therapeutic targets for the development of better drugs to treat the disease. Several works have described the importance of amino acids in the life cycle of $T$. cruzi, which, beyond their participation in protein synthesis and energetic metabolism, are involved in different other biological functions in the parasite. Although previous studies pointed to branched chain amino acids (BCAA - leucine, isoleucine and valine) as relevant components of $T$. cruzi metabolism, it is curious that there are still few reports in the literature on the identification of relevant roles for BCAA in the the biology of parasite by themselves or in association to other amino acids. The aim of this project is to: (1) Evaluate the biological role of BCAAs in the life cycle of the parasite, with special emphasis on differentiation processes; (2) Characterize the first metabolic step for BCAA in T. cruzi: their uptake from the extracellular medium. (2) Kinetically characterize whether the enzymes transaminases tyrosine aminotransferase TAT and aspartate aminotransferase ASAT catalyze the deamination / amination reaction of the BCAA derivatives. (3) Identify the enzymes responsible for the BCAA deamination and kinetically characterize them. (4) Characterize the functional role of the enzymatic complex dehydrogenase of branched alpha-ketoacids (BCAKDH). (5) Study the intracellular localization of the BCAKDH complex in the different stages of the parasite. (6) Investigate the functionality of the proteins associated with the BCAKDH complex.
\end{abstract}

Keywords: Trypanosma Cruzi. Amino Acids. Leucine. Valine. Isoleucine. Chagas' Disease. Differentiation. Metacyclogenesis. Transport. 
CAPÍTULO 1: INTRODUCÃO 


\section{$\underline{1.1 \text { A doenca de Chagas }}$}

A doença de Chagas (Tripanossomíase americana) é uma zoonose causada pelo protozoário flagelado Trypanosoma cruzi, o qual é transmitido por insetos hematófagos da família Reduviidae (DE SOUZA, 2002). Os reservatórios naturais do parasita compreendem uma ampla variedade de marsupiais e mamíferos placentários autóctones do continente americano, com os quais o parasita tem co-evoluído por mais de dez milhões de anos (URBINA, 2010). Essa infecção foi descrita em humanos pela primeira vez há cento e oito anos pelo médico Carlos Chagas em Minas Gerais - Brasil (CHAGAS, 1909). Atualmente, a doença de Chagas constitui um problema relevante de saúde pública mundial, uma vez que está distribuída endemicamente em 22 países do continente americano (Esquema 1), nos quais afeta de 7 a 8 milhões de pessoas, sendo relatadas de 10.000 a 14.000 mortes por ano (WHO, 2012; 2014). Apesar das expressivas taxas de prevalência, segundo a World Health Organization (WHO), a doença de Chagas é uma das 13 enfermidades tropicais mais negligenciadas do mundo (HOTEZ et al., 2007).

Esquema 1 - Distribuição mundial da doença de Chagas.

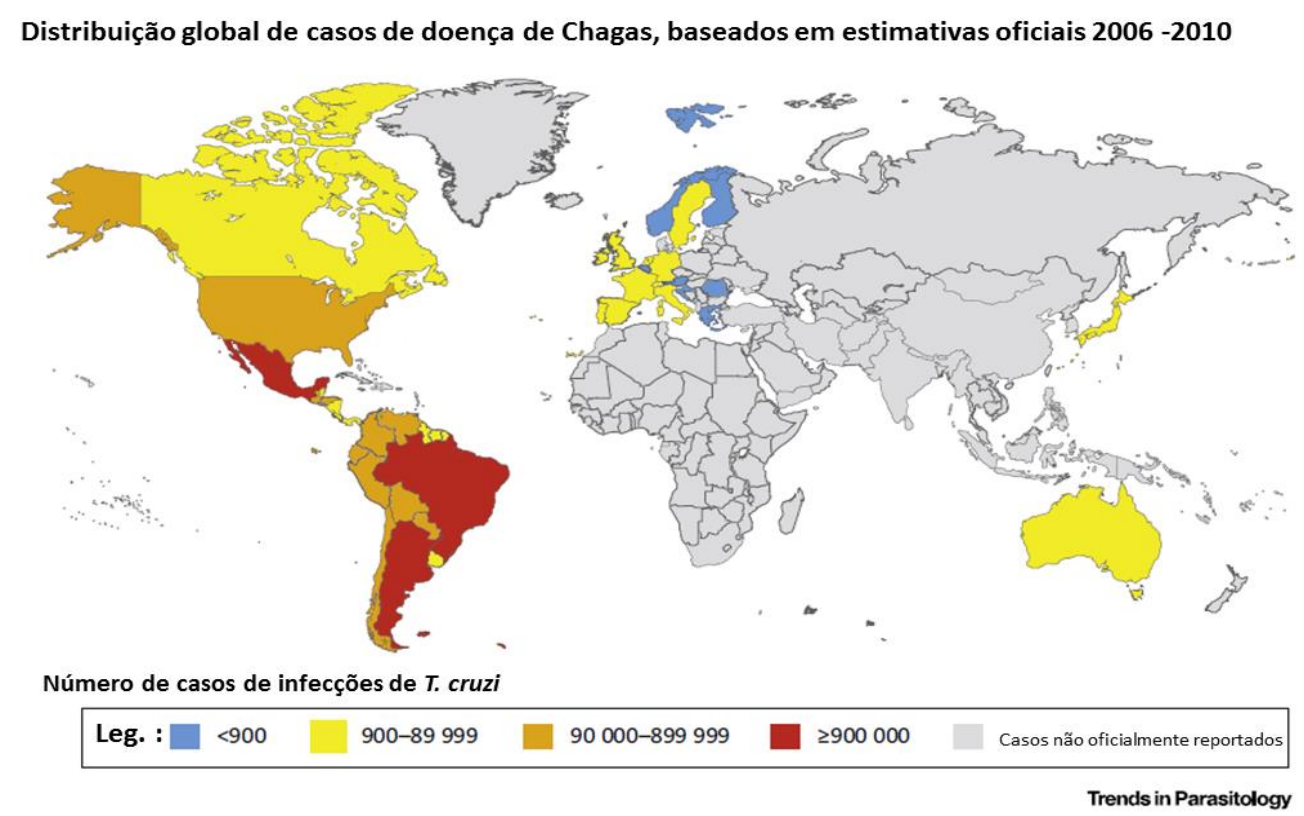

Fonte: adaptado de (PEREZ et al., 2015).

O T. cruzi sobrevive em uma ampla faixa de condições ambientais, desenvolvendo complexas mudanças morfológicas durante seu ciclo de vida, no qual alterna entre um inseto vetor e um hospedeiro vertebrado (BRENER, 1973). As principais formas do parasita descritas na 
literatura são: amastigota intracelular (A-forma replicativa e infectiva), epimastigota intracelular (Ei-forma intermediária entre amastigota e tripomastigota sanguíneo, replicativa e não infectiva) e tripomastigota sanguíneo (T-forma infectiva não replicativa) no interior do hospedeiro mamífero; e epimastigota (E-forma replicativa não infectiva) e tripomastigota metacíclico (Mforma infectiva não replicativa) no inseto vetor (Esquema 2). O processo de diferenciação no qual as formas replicativas $\mathrm{E}$ se transformam em formas $\mathrm{M}$ infetivas, é chamado de metaciclogênese, e no ciclo natural acontece no tubo digestivo do inseto vector (ALMEIDA-DE-FARIA et al., 1999; TYLER; ENGMAN, 2001).

Esquema 2 - Ciclo de vida do Trypanosoma cruzi

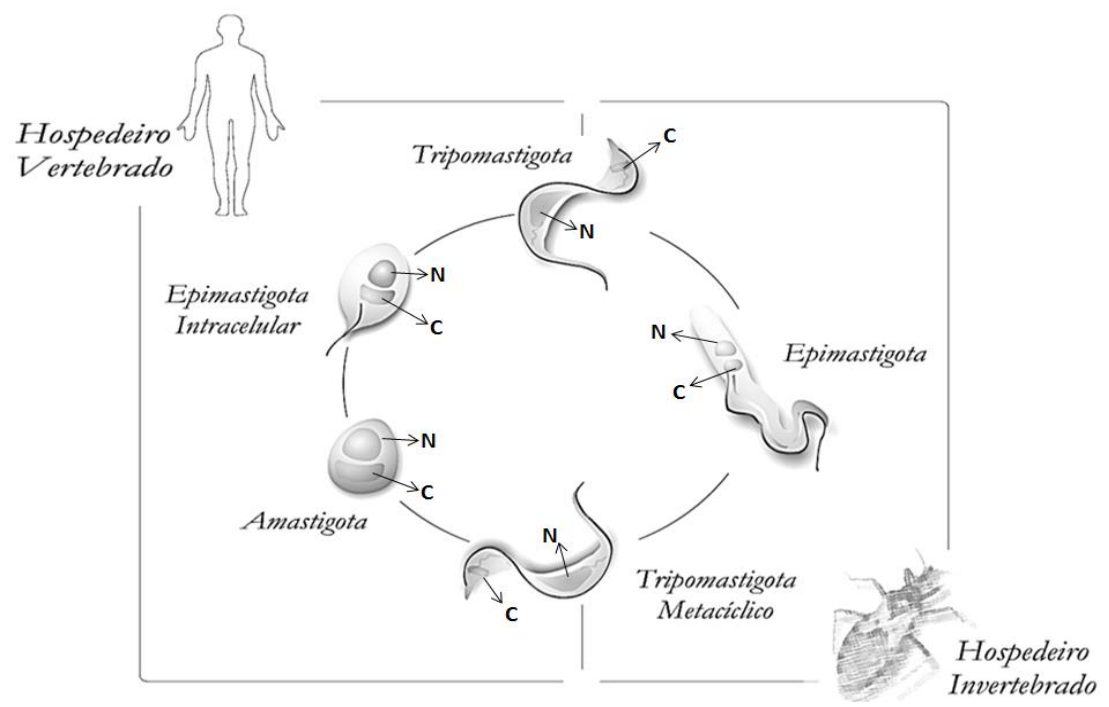

Fonte: Adaptado de (PAES et al., 2011). N, núcleo e C, cinetoplasto.

A forma clássica de transmissão da doença envolve a intervenção de insetos vetores que ao realizarem o repasto sanguíneo no hospedeiro vertebrado, depositam junto com as fezes formas M, que penetram a pele e invadem as células. Existem outras formas de transmissão que ocorrem por transfusão sanguínea, via placentária ou via oral por ingestão de alimentos contaminados com parasitas (COURA, 2013; NORMAN; LÓPEZ-VÉLEZ, 2014).

A doença apresenta duas fases clínicas em humanos: uma fase aguda e outra crônica. A fase aguda acontece no início da infecção e dura entre 4 e 8 semanas, sendo geralmente assintomática, porém, sintomas inespecíficos como febre e dores de cabeça podem ocorrer. Essa fase caracteriza-se por intensa parasitemia presente em praticamente todos os órgãos e tecidos do 
organismo. A fase crônica caracteriza-se por uma parasitemia reduzida ou indetectável pelos métodos de diagnóstico tradicionais, e por uma robusta resposta humoral em pacientes imunocompetentes. Essa fase pode apresentar diferentes formas. A forma indeterminada, acomete $70 \%$ dos pacientes, é assintomática, e pode durar toda a vida do paciente (MONCAYO; ORTIZ YANINE, 2006). Por sua vez, as formas sintomáticas mais frequentes (que acometem aproximadamente um terço dos pacientes crônicos) apresentam-se como cardiopatias (PARKER; SETHI, 2011; PUNUKOLLU et al., 2007; RASSI et al., 2010) e/ou alterações gastrointestinais. Esses sintomas podem apresentar vários graus de severidade, podendo levar ao óbito (GATTUSO; KAMM, 1993; MATSUDA et al., 2009).

\section{1. 1 Quimioterapia}

A quimioterapia disponível para a doença de Chagas está baseada em duas drogas descobertas há mais de 40 anos: Nifurtimox (NFX) e Benzonidazol (BZN) (PINTO DIAS, 2006). O NFX (Lampit®, Bayer®; 5-nitrofuran (3-metil-4-(5'-nitrofurfurideneamina) tetrahidro-4H-1,4tiazina-1,1-dioxida), é um derivado nitro-heterocíclico que mostrou-se em experimentos in vitro como o composto com maior atividade anti-T. cruzi e menor toxicidade. O mecanismo de ação do NFX está relacionado com a produção de nitro-radicais-aniônicos os quais, na presença de oxigênio, impedem a detoxificação dos radicais livres no parasita (DOCAMPO; MORENO, 1986). O BNZ (Rochagan®, Radlanil R, Roche®; N-benzil-2-nitroimidazol acetamida) é um 2nitroimidazol com atividade anti-T. cruzi em testes in vitro e in vivo (PACKCHANIAN, 1957). A ação do BZN está relacionada com a nitrorredução dos componentes do parasita, a modificação química do DNA, assim como também dos lipídeos e proteínas do parasita (COURA, 2009; POLAK; RICHLE, 1978;). Atualmente, o uso desses medicamentos está sujeito a limitações. Apesar do fato de ambos serem eficazes na fase aguda da doença, sua eficiência na fase crônica é discutível. Na fase aguda relatou-se entre 70 e $75 \%$ de cura, sendo avaliada a parasitemia como parametro de cura. Porém, na fase crônica, os dados são controversos, sendo relatada uma taxa de cura de aproximadamente 30\% (APT; ZULANTAY, 2011). Além disso, ambos os compostos, apresentam uma ampla variedade de efeitos adversos, desde dermatite a convulsões e alucinações (COURA, 2009).

Dada à necessidade de desenvolver novas alternativas terapêuticas para tratar a doença de Chagas, estudos promissores vêm sendo realizados sobre a inibição das enzimas que participam 
de diversas vias metabólicas relevantes ao parasita, como a biossíntese de ergosteróis, as cisteína proteases (cruzipaina), o metabolismo de pirofosfatos, a síntese e metabolismo de tripanotiona e a recuperação de purinas (URBINA, 2010). Contudo, há dificuldades na proposta de um medicamento eficaz, sem efeitos colaterais e de fácil aplicação clínica para tratar esta doença (APT; ZULANTAY, 2011; SILBER et al., 2005;).

\subsubsection{Características do Trypanosoma cruzi}

T. cruzi, é um parasita eucariota unicelular que pertence ao super grupo Excavata, grupo Euglenozoa, subgrupo Kinetoplastea, agrupamento Metakinetoplastina e gênero Trypanosoma (ADL et al., 2005). Todos os membros do gênero Trypanosoma apresentam um flagelo que emerge a partir de uma invaginação denominada bolsa flagelar. De acordo com o estágio de desenvolvimento, o flagelo pode ter elongações que variam entre 2 e $20 \mu \mathrm{m}$ de comprimento (DE SOUZA, 2002).

Uma das singularidades do T. cruzi é a morfologia e estrutura da sua única mitocôndria, que percorre todo o corpo do parasita. Essa organela apresenta os compartimentos clássicos conhecidos como a matriz, a membrana externa e interna (MEM, MIM) e o espaço intermembrana (PAES et al., 2011; SOUZA, 2008). O genoma mitocôndrial está organizado em uma estrutura denominada cinetoplasto, contendo uma rede de 25 a 30 moléculas de DNA circular de grande tamanho (maxicírculos, de aproximadamente $25 \mathrm{~Kb}$ ) e de entre 20 e 30 mil moléculas de DNA circular de pequeno tamanho (minicírculos de aproximadamente $1 \mathrm{~kb}$ ) (RIOU; DELAIN, 1969). O DNA do genoma mitocôndrial (kDNA) constitui aproximadamente $30 \%$ do DNA total da célula. O cinetoplasto se localiza próximo ao corpúsculo basal flagelar (Figura 3), ao qual o kDNA está conectado por um filamento transmembranar conhecido como complexo tripartito de adesão (tripartite attachment complex) (LIU et al., 2009; OGBADOYI et al., 2003). Uma das características mais notáveis ao longo do ciclo de vida do parasita é a mudança de posição do cinetoplasto com relação ao núcleo, sendo que nas formas E, o cinetoplasto e a bolsa flagelar estão em posição anterior ao núcleo e nas formas T ou M, o cinetoplasto está na parte posterior ao núcleo (Esquema 2).

O parasita apresenta outras organelas com características únicas como o glicossomo, compartimento derivado dos peroxissomos que contém as primeiras sete enzimas da via glicolítica (Michaels et al., 2006); os acidocalcissomos, organelas que, embora presente em uma 
grande variedade de organismos eucariotas, também possue características e funções únicas em T. cruzi, como conter uma alta concentração de fósforo (pirofosfato e polifosfato) complexados com $\mathrm{Ca}^{2+}$, os quais são importantes nos processos de osmoregulação (Esquema 3) (CAZZULO, 1994; CAZZULO et al., 1997; DOCAMPO; MORENO, 1999; ROHLOFF et al., 2004; SCOTT et al., 1997; URBINA, 1994).

Esquema 3 - Estrutura e organelas do Trypanosoma cruzi.

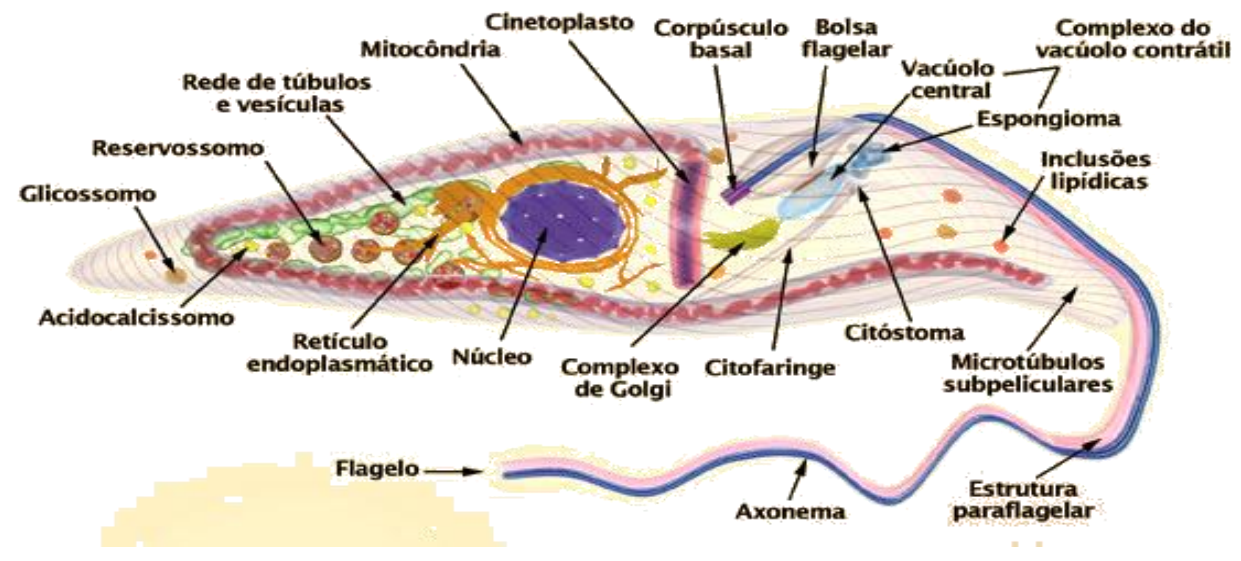

Fonte (TEIXEIRA et al., 2012)

Os reservossomos, são descritos como organelas que estocam macromoléculas como lipídeos e proteínas (SOARES, 1999). Soares e colaboradores (1999) sugeriram que o estresse nutricional poderia resultar na acidificação do conteúdo luminal do reservosomo, o que por sua vez acarretaria uma ativação de enzimas de tipo lisossomais contidas no interior destas organelas, sendo assim, este seria um compartimento pré-lisossomal, onde seriam degradadas as macromoléculas armazenadas (FIGUEIREDO et al., 2004; SOARES et al., 1992). Mais recentemente, uma análise proteômica do reservossomo identificou vários tipos de hidrolases, cisteino-proteases, alfa manosidases, ácido fosfatases, calpaina cisteino peptidases, lipases e serina carboxipeptidases S28, proteínas características de organelas lisossomais (SANT'ANNA et al., 2009) Sabe-se que durante a metaciclogênese essas organelas reduzem seu tamanho até desaparecer completamente nas formas M. Acredita-se que as proteínas contidas nos reservossomos são degradadas durante a metaciclogênese (FRANKE DE CAZZULO et al., 1994) o fato anterior sugere que o parasita degradaria as macromoléculas armazenadas no reservosomo para produzir aminoácidos que serviriam para a produção energética do parasita ao longo deste processo de diferenciação. Consequentemente, foi demonstrado também que o consumo de 
aminoácidos é favorecido em epimastigotas durante condições de estresse nutricional (URBINA, 1994).

\subsection{Metabolismo de $T$. cruzi}

\subsubsection{Transporte de metabólitos}

Os processos de transporte são os primeiros passos de toda via metabólica, e destes depende a disponibilidade de alguns substratos no interior da célula. Isto é importante nos tripanosomatídeos, sendo que a sua sobrevivência e adaptação nos diferentes ambientes nos quais se desenvolvem, depende da sua capacidade de utilizar os metabólitos disponíveis (PEREIRA et al., 2008).

Parte do metabolismo de T. cruzi está baseado na degradação de aminoácidos, não só como fonte de carbono mas também como reservatório de energia (BRINGAUD et al., 2006; ZELEDON, 1960). A prolina é um dos metabólitos degradados pelo T. cruzi, assim como asparagina, glutamina, glutamato, leucina (Leu) e isoleucina (Ile). Conhecer os mecanismos de incorporação é relevante, uma vez que diversos desses aminoácidos não podem ser sintetizados pelo parasita e, a sua disponibilidade intracelular, depende exclusivamente do transporte do meio extracelular ou da degradação de proteínas (BERRIMAN et al., 2005; CONTRERAS et al., 1985). Além dos mecanismos de incorporação, o estudo das proteínas que compõem os transportadores de aminoácidos também é relevante, pois estas são as primeiras a terem contato com os solutos do meio e atuam na superficie celular do parasita, como sinalizadores (SILBER et al., 2005). Conhecer o funcionamento deste tipo de processos é chave no desenvolvimento de novas terapias.

Até o momento, foram caracterizados bioquímicamente os sistemas de transporte para arginina, prolina, glutamato, lisina, aspartato e cisteína (Tabela 1), mas a estrutura e os mecanismos moleculares do funcionamento dos transportadores de aminoácidos em T. cruzi são em geral desconhecidos. Os únicos genes de transportadores de metabólitos clonados e expressos funcionalmente, são os do transportador de glicose (Glc) (TETAUD et al., 1994;), arginina, prolina, espermidina e lisina (Tabela 1). Alguns parâmetros cinéticos para certos metabólitos têm sido descritos, incluindo em alguns casos os seus inibididores e pH ótimos (Tabela 1). 
Tabela 1 - Transporte de metabólitos caracterizados em T. cruzi.

\begin{tabular}{|c|c|c|c|c|c|c|c|c|c|}
\hline \multicolumn{2}{|c|}{ Metabólito } & $\mathbf{K m}$ & $V_{\max }(\mathbf{p m o l}$ & Ea & Inibidores & Força & pH & Ref & Gene associado \\
\hline Arginina & $\begin{array}{l}\text { Alta afinidade } \\
\text { Baixa afinidade }\end{array}$ & $\begin{array}{c}0,0042 \\
0,35\end{array}$ & 19 & $\begin{array}{l}31,1 \\
324\end{array}$ & $\begin{array}{l}\text { D-Arg } \\
\text { Met }\end{array}$ & $\begin{array}{l}\mathrm{H}^{+} \\
\mathrm{H}^{+}\end{array}$ & $\begin{array}{l}5,5 \\
4,5\end{array}$ & $\begin{array}{l}\text { PEREIRA et al. (1999) } \\
\text { CANEPA et al. (2004) }\end{array}$ & $\begin{array}{l}\text { TcAAAP411 (Tc00.1047053511411.30) } \\
\text { CARRILLO et al. (2010) }\end{array}$ \\
\hline Prolina & $\begin{array}{l}\text { Sistema A } \\
\text { Sistema B }\end{array}$ & $\begin{array}{l}0,31 \\
1,36\end{array}$ & 32.5 & 79,5 & $\begin{array}{l}\text { Cys, Ala } \\
\text { Cys, Ala }\end{array}$ & $\begin{array}{c}\mathrm{H}^{+} \\
\mathrm{H}^{+} / \mathrm{ATP}\end{array}$ & $\begin{array}{c}4,5-5 \\
-\end{array}$ & SILBER et al. (2002) & $\begin{array}{c}\text { TcAAAP069 (Tc00.1047053504069.12) } \\
\text { SAYÉ et al. (2014) }\end{array}$ \\
\hline Cisteina & - & 0,0495 & 13 & - & - & $\mathrm{H}^{+}$ & 5 & CANEPA et al. (2009) & - \\
\hline Histidina & Ativo & 0,12 & 240 & 55,2 & & $\mathrm{H}^{+}$ & 6 & $\begin{array}{l}\text { (BARISON et al., } \\
\text { 2016) }\end{array}$ & \\
\hline Lisina & - & 0,025 & 2,4 & - & Ser & - & - & $\begin{array}{l}\text { HAMPTON (1970); } \\
\text { (INBAR et al., 2012) }\end{array}$ & $\begin{array}{l}\text { TcAAP7 (Tc00.1047053511545.80) } \\
\text { INBAR et al. (2012) }\end{array}$ \\
\hline Glutamato & - & 0,30 & 49,17 & 52,38 & Asp & $\mathrm{H}^{+}$ & 5 & $\begin{array}{l}\text { SILBER, A. et al. } \\
(2006)\end{array}$ & - \\
\hline Aspartato & - & 0,032 & 3,4 & - & - & $\mathrm{H}^{+}$ & 4 & (CANEPA et al., 2005) & - \\
\hline GABA & & 0,33 & 38,4 & 19,68 & - & $\mathrm{Na}^{+} / \mathrm{H}^{+}$ & 8 & $\begin{array}{l}\text { GALVEZ ROJAS et al. } \\
(2015)\end{array}$ & - \\
\hline Espermidina & & 0,014 & 3,6 & - & $\begin{array}{l}\text { Poliamina } \\
\text { Amino } \\
\text { acidos, } \\
\text { putrecina }\end{array}$ & - & & $\begin{array}{l}\text { CARRILLO et al. } \\
\text { (2006) }\end{array}$ & $\begin{array}{l}\text { TcPAT12 GenBank; AY526253 } \\
\text { CARRILLO et al. (2006) }\end{array}$ \\
\hline Glicose & Facilitado & 0,315 & $7,7 *$ & - & D-fructose & - & - & $\begin{array}{l}\text { (BARRETT et al., } \\
\text { 1998) }\end{array}$ & TcHT1. (TETAUD et al., 1994) \\
\hline Leucina & & 1,07 & 470 & & & & & & \\
\hline Isoleucina & $\begin{array}{c}\text { Transportador } \\
\text { de } \\
\text { BCAA }\end{array}$ & 0,47 & 80 & 51,30 & BCAAs & $\mathrm{H}^{+} / \mathrm{ATP}$ & 6 & $\begin{array}{l}\text { Esse trabalho } \\
\text { MANCHOLA et al } \\
2015\end{array}$ & - \\
\hline Valina & & 1,96 & 165 & & & & & & \\
\hline
\end{tabular}

Adaptado de (MANCHOLA. et al., 2015). Os valores de $\mathrm{K}_{\mathrm{m}}$ foram normalizados a $\mathrm{mM}$ de substrato. Os valores de $V_{\mathrm{max}}$ foram normalizados a pmol min ${ }^{-1}$ por $10^{7}$ células, exetuando o $\left(^{*}\right)$ que está expresso em $\mathrm{nmol} \mathrm{min}^{-1} \mathrm{mg}$ de protrina 


\subsubsection{Vías metabolicas de $T$. cruzi}

O parasita alterna ao longo do seu ciclo de vida ente ambientes "ricos e pobres" em glucose (Glc), tendo que se adaptar para metabolizar os recursos de carbono e energia disponíveis. Sabe-se que, diferentemente de outros organismos eucariotas, T. cruzi não é capaz de armazenar Glc em forma de polissacarídeos ou carboidratos, sendo necessária a incorporação deste composto do meio extracelular. Sabe-se que os epimastigotas por exempplo, consomem Glc durante a fase exponencial de crescimento, e mudam o seu metabolismo para um baseado no consumo de aminoácidos durante a fase estacionária (CAZZULO 1992, 1994; BARISON 2017). Além disso, foi descrito que no meio intracelular, os partasitas não transportam glicose, sendo o metabolismo de Pro um dos seus sustentos energéticos (SILBER et al., 2009). Quando T. cruzi consome Glc produz metabólitos reduzidos como succinato e amônio (CAZZULO, 1994). De fato, o processo de oxidação da Glc em T. cruzi não apresenta uma inibição na presença de oxigênio, ocorrendo taxas semelhantes do consumo de Glc tanto em anaerobiose quanto aereobiose, sendo este fenômeno denomninado "fermentação aeróbica" (CANNATA e CAZZULO, 1984; CAZZULO et al., 1988; CAZZULO, 1994). Nestas condições a Glc, que não é completamente degradada, pode render em $\mathrm{CO}_{2}$, ácidos mono e dicarboxílicos e pequenas quantidades de acetato e piruvato como produtos finais de oxidação (BOWMAN et al., 1963). O processo glicólitico apresenta também como particularidades, a compartimentalização das sete primeiras enzimas responsáveis pela oxidação da Glc no glicossomo (OPPERDOES; BORST, 1977) e a ausência dos pontos regulatórios clássicos desta via (enzimas hexoquinase e fosfofrutoquinase, Esquema 4) (URBINA; CRESPO, 1984). Acredita-se que a compartimentalização desta via estaria compensando a perda dos pontos regulatórios, protegendo a célula dos efeitos tóxicos desta desregulação (MICHELS, 2006; BAKKER, 2000). Devido à heterogeneidade no conteúdo enzimático que podem apresentar os glicossomos nas diferentes fases do T. cruzi, foi proposto que esta organela estaria conferindo um tipo de plasticidade metabólica que permite ao parasita sobreviver nos diferentes ambientes ao longo do seu ciclo de vida (GUALDRÓN-LÓPEZ et al., 2012). 


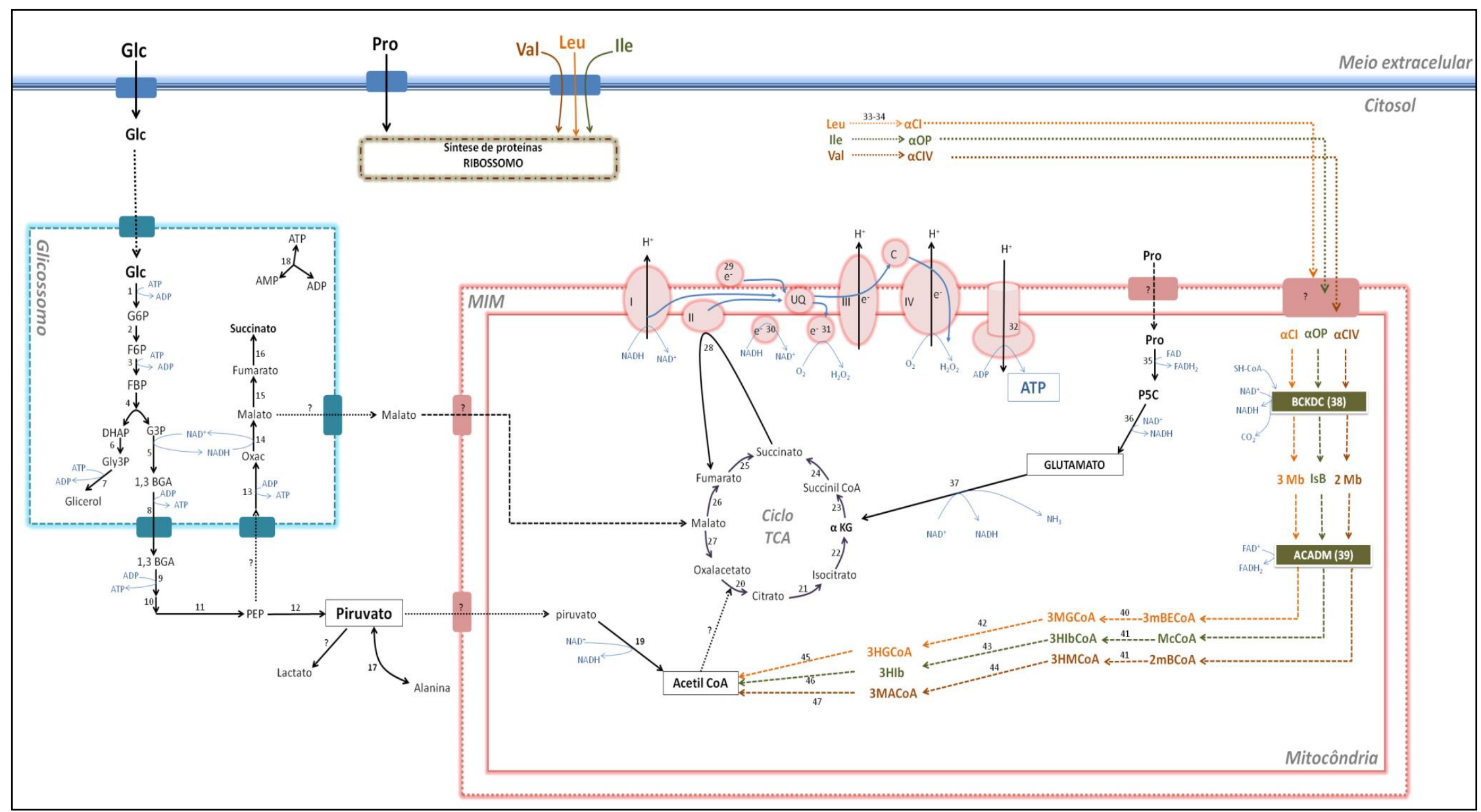

Esquema 4 - Vías metabólicas de T. cruzi. As setas pontilhadas representam as vias metabólicas hipotéticas não caracterizadas. Os aminoácidos ramificados estão descados em cores diferentes incluindo as enzimas comuns aos três BCAA. Modificado de (BRINGAUD et al., 2006; MICHELS et al., 2006) 


\section{Lista de enzimas}

\begin{tabular}{|c|l|}
\hline 1 & Hexoquinase \\
\hline 2 & Glicose-6-fosfato isomerase \\
\hline 3 & Fosfofrutoquinase \\
\hline 4 & Aldolase \\
\hline 5 & Gliceraldeído-3-fosfato desidrogenase \\
\hline 6 & Glicerol-3-fosfato desidrogenase \\
\hline 7 & Glicerol quinase \\
\hline 8 & Fosfoglicerato quinase glicosssomal \\
\hline 9 & Fosfoglicerato quinase citosólica \\
\hline 10 & Fosfoglicerato mutase \\
\hline 11 & Enolase \\
\hline 12 & Piruvato quinase \\
\hline 13 & Fosfoenolpiruvato carboxiquinase \\
\hline 14 & Malato desidrogenase glicossomal \\
\hline 15 & Fumarase \\
\hline 16 & $\begin{array}{l}\text { Fumarato redutase } \\
\text { dependenteglicossomal }\end{array}$ \\
\hline 17 & Alanina aminotransferase \\
\hline 18 & Adenilato quinase glicossomal \\
\hline 19 & Complexo piruvato desidrogenase \\
\hline 20 & Citrato sintase \\
\hline 21 & Aconitase \\
\hline 22 & Isocitrato desidrogenase \\
\hline 23 & $\begin{array}{l}\text { Complexo } \alpha \text {-cetoglutarato } \\
\text { desidrogenase }\end{array}$ \\
\hline 24 & Succinil CoA-sintetase \\
\hline 25 & $\begin{array}{l}\text { Fumarato } \\
\text { dependente redutase } \\
\text { Mitocondrial }\end{array}$ \\
\hline 26 & $\begin{array}{l}\text { Fumarase mitocondrial } \\
5 \text {-triose- }\end{array}$ \\
\hline 27 & Malato desidrogenase mitocondrial \\
\hline 28 & Succinato desidrogenase \\
\hline 29 & Glicerol-3-fosfato desidrogenase \\
\hline 30 & NADH desidrogenase \\
\hline 31 & Oxidases alternativas \\
\hline 32 & F F $_{0}$ F $_{1}$ ATP sintase \\
\hline 33 & Tirosina amino transferase \\
\hline 34 & Aspartato amino transferase \\
\hline 35 & Prolina desidrogenase \\
\hline 36 & Pirrolina-5-carboxilato desidrogenase \\
\hline 37 & Glutamato desidrogenase \\
\hline 38 & $\begin{array}{l}\text { BCKDC Branched-chain } \alpha \text {-ketoacid } \\
\text { dehydrogenase complex }\end{array}$ \\
\hline 13 & Aminoase de alfa ceto ácidos \\
\hline
\end{tabular}

\begin{tabular}{|l|l|}
\hline 39 & ACDM acil-coenzima A desidrogenase. \\
\hline 40 & Metilcrotonil CoA carboxilase \\
\hline 41 & Enoil CoA hidratase \\
\hline 42 & Metilglutaconil CoA hidratase \\
\hline 43 & 3-hidroxibutiril CoA hidrolase \\
\hline 44 & 3-hidroxiacil CoA desidrogenase \\
\hline 45 & Hidroximetilglutaril-CoA liase \\
\hline 46 & 3-hidroxiacil CoA desidrogenase \\
\hline 47 & Acetil-CoA aciltransferase \\
\hline
\end{tabular}

\section{Metabólitos intermediários}

\begin{tabular}{|l|l|}
\hline Glc & Glicose \\
\hline G6F & Glicose-6-fosfato \\
\hline F6F & Frutose-6-fosfato \\
\hline FBF & Frutose-1,6-bisfosfato \\
\hline DHAP & Di-hidroxi acetona fosfato \\
\hline G3P & Gliceraldeído 3 fosfato \\
\hline Gly3P & Glicerol 3 fosfato \\
\hline 1,3 BGA & 1, 3 Bifosfoglicerato \\
\hline PEP & Fosfoenol-piruvato \\
\hline Oxac & Oxaloacetato \\
\hline $\boldsymbol{\alpha}$ KG & Alfacetoglutarato \\
\hline $\boldsymbol{\alpha}$ CA-BCAA & $\begin{array}{l}\text { Alfacetoácidos derivados } \\
\text { de BCAA }\end{array}$ \\
\hline a CI & Ácido alfa ceto isocapróico \\
\hline $\boldsymbol{\alpha}$ CP & $\begin{array}{l}\text { Ácido alfa } 3 \\
\text { oxopentanóico }\end{array}$ \\
\hline $\boldsymbol{\alpha}$ CIV & Ácido alfa ceto isovalerico \\
\hline 3Mb & 3-metilbutanoil-CoA \\
\hline IsB & Isobutiril-CoA \\
\hline 2Mb & 2-metilbutanoil-CoA \\
\hline 3MBECoA & 3-metilbut-2-enoil-CoA \\
\hline McCoA & 2-Metacilil-CoA \\
\hline 2MBBCoA & $\begin{array}{l}\text { 2-metilbut-2-metilbutiril- } \\
\text { CoA }\end{array}$ \\
\hline 3MGCoA & 3-metilglutaconilCoA \\
\hline 3HIBCoA & 3-HidroxisobutirilCoA \\
\hline 3HMCoA & $\begin{array}{l}\text { 3 } \\
\text { metilbutirilCoA }\end{array}$ \\
\hline 3HGCoA & $\begin{array}{l}\text { s-3-hidroxi-3- } \\
\text { metilglutarilCoA }\end{array}$ \\
\hline 3HICoA & 3 hidroxiisobutirato \\
\hline 2MACoA & 2 metilacetoacetilCoA \\
\hline
\end{tabular}

1.3 Aminoácidos ramificados ou BCAA (Branched Chain Amino Acids) 
A leucina, valina e isoleucina, também conhecidos como aminoácidos de cadeia ramificada (BCAA), são os aminoácidos mais hidrofóbicos e por isso, exercem papéis fundamentais na determinação das estruturas protéicas globulares e na interação entre os domínios proteicos transmembranais (BROSNAN; BROSNAN, 2006). Esses aminoácidos são essenciais (não são sintetizados pelas células de mamífero, devem ser incorporados da dieta) e representam aproximadamente $35 \%$ dos aminoácidos que compõem as proteínas musculares (HARPER et al., 1984). Devido a isso, em células de mamíferos, o metabolismo dos BCAA está diretamente relacionado aos sistemas de transporte, podendo também influenciar a cinética de outros sistemas que os requerem (KURPAD et al., 2006). Exemplo disso é a relação entre a glutamina intracelular, os BCAA e a homeostase protéica muscular, onde os BCAA constituem o maior recurso de nitrogênio e esqueletos carbonados para a síntese de glutamina (CAMERON et al., 2000).

O esquema 5 representa a via de catabolismo dos BCAA. Podemos observar etapas comuns aos três aminoácidos sendo a primeira delas a reação catabólica de desaminação dos BCAA mediante uma reação de transaminação reversível que rende glutamato e $\alpha$-cetoácidos de cadeia ramificada (branched-chain $\alpha$-keto acids -BCAK). (BIXEL et al., 1997). 
Esquema 5 - Representação da via catabólica dos aminoácidos de cadeia ramificada.

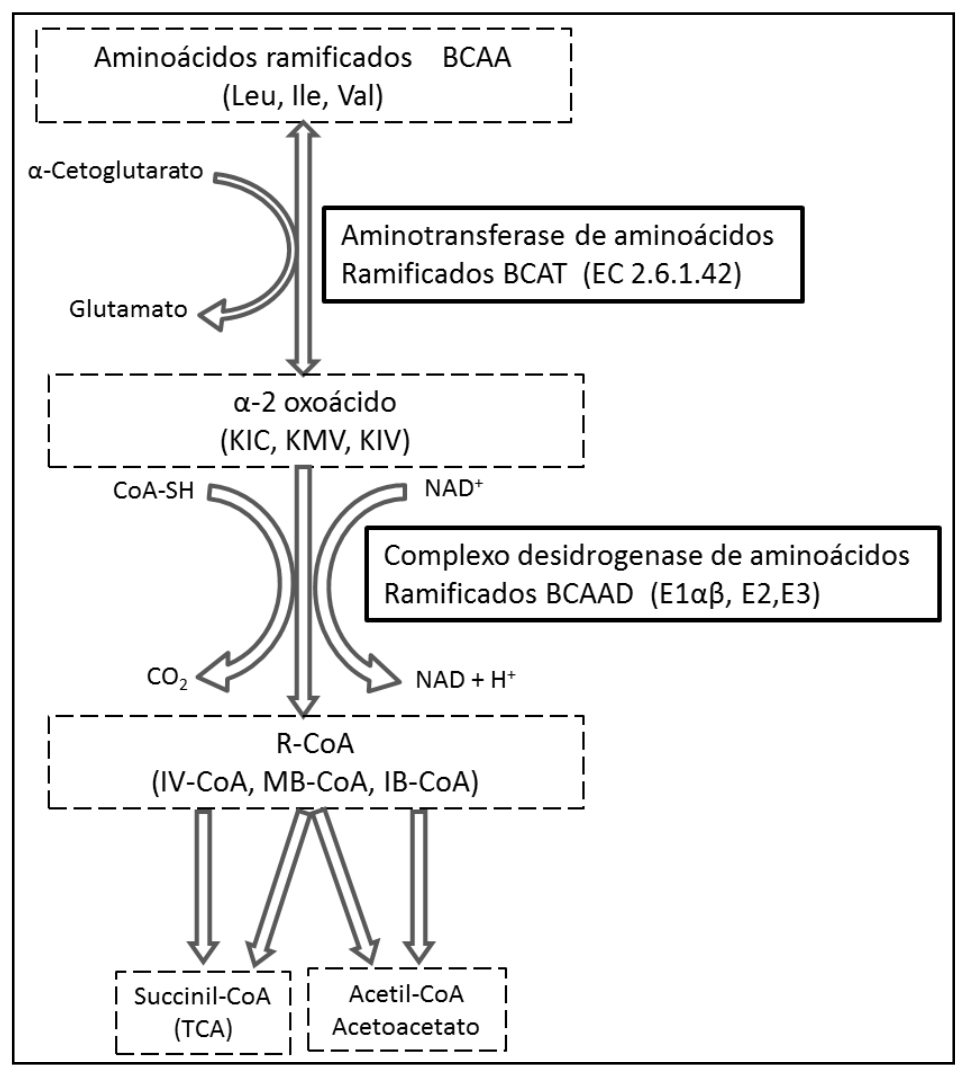

TCA - ciclo do ácido tricarboxílico

KIC - Ácido alfa cetoisocapróico

KIV - Ácido alfa ceto isovalérico

KMV Ácido alfa 3 metil 2

oxopentanóico

CoA-SH - coenzima A reduzida

IB-CoA - isobutiril-CoA

MB-CoA - $\alpha$-metilbutiril-CoA

IV-CoA - isovaleril-CoA

R-CoA - acil-CoA

\section{Fonte:}

Adaptado de BROSNAN; BROSNAN (2006).

\subsubsection{Transaminação e degradação de aminoácidos ramificados}

Como mencionado, o primeiro passo na degradação dos aminoácidos ramificados é uma transaminação reversível, produzindo um alfa-cetoácido ramificado. Esse passo em mamíferos é catalisado por uma transaminase específica para aminoácidos ramificados (Branched Chain Amino Transferase-BCAT) (EC 2.6.1.42) (BIXEL et al., 1997). Estes tipos de enzimas são dependentes de piridoxal fosfato (PLP), e caraterizam-se por realizar duas hemi-reações sequenciais do tipo ping-pong, nas quais o grupo amino de um substrato é transferido para o segundo, produzindo dois produtos diferentes. Tem sido descrito que, embora este tipo de enzimas seja reversível, a direção da reação está determinada pelas concentrações relativas dos substratos (HUTSON, 2001). Os seguintes passos na via são catalizados pelo complexo enzimático denominado desidrogenase de aminoácidos ramificados (Branched Chain Amino Acid Dehydrogenase- BCKDC), que catalisa a descarboxilação oxidativa irreversível dos alfa-cetoácidos ramificados (PERHAM e PACKMAN, 1989; Perham, 1991). As reações que o complexo catalisa (ver reações 1-4 na Figura 5) envolvem ações sequenciais de 3 componentes enzimáticos: 
1.3.2 Componente E1 (2-oxoácido desidrogenase): constutuído por duas subunidades enzimáticas: $T c \mathrm{E} 1 \beta$ ( $\beta$-2-oxoisovalerato desidrogenase, EC 1.2.4.4) e $T c \mathrm{E} 1 \alpha$ ( $\alpha$-2oxoisovalerato desidrogenase, EC 1.2.4.4) catalisam a descarboxilação oxidativa dos alfacetoácidos ramificados provinentes da transaminação da leucina, isoleucina e valina, usando tiamina pirofosfato (TPP) como cofator, produzindo uma molécula intermediária hidroxilacila-TPP (Figura 4 passo 1) e uma molecula de $\mathrm{CO}_{2}$. Subsequentemente, catalisa a acilação redutiva do cofator ácido lipóico que está covalentemente ligado ao componente E2 (Esquema 6, passo 2) (YEAMAN, 1986).

1.3.3 Componente E2 (diidrolipoil transacilase EC 2.3.1.168): constituído por uma unidade enzimática, na qual o grupo acila da molecula intermediaria hidroxi-acila-TPP é transferido pelo E2 para o receptor CoA, reduzindo o ácido lipóico (Esquema 6, passo 3).

1.3.4 Componente E3 (diidrolipoil desidrogenase EC 1.8.14): Também constituído por uma subunidade, na qual o cofator ácido lipóico reduzido é reoxidado pelo $\mathrm{E} 3$, usando $\mathrm{FAD}^{+} \mathrm{e}$ $\mathrm{NAD}^{+}$como aceptor final de elétrons (Esquema 6, passos 4-5) (YEAMAN, 1989).

Em conjunto, as reações acima descritas catalisam a ruptura da ligação carbonocarbono dos alfa-cetoácidos ramificados, transduzindo a sua energia a substratos oxidáveis (acetil-CoA) ou coenzimas reduzidas (NADH), produzindo $\mathrm{CO}_{2}$ como produto da descarboxilação. Em humanos, este complexo enzimático encontra-se na mitocôndria e está formado por 24 cópias de $\mathrm{E} 2$ as quais formam um núcleo de três octaedros no qual se

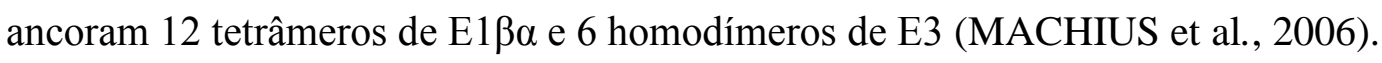


Esquema 6 - Representação do complexo enzimático desidrogenase de aminoácidos ramificados, exemplificando a degradação do ácido-4-metil-2-oxopentanoico (alfa-cetoácido ramificado derivado da des-aminação de Leu).

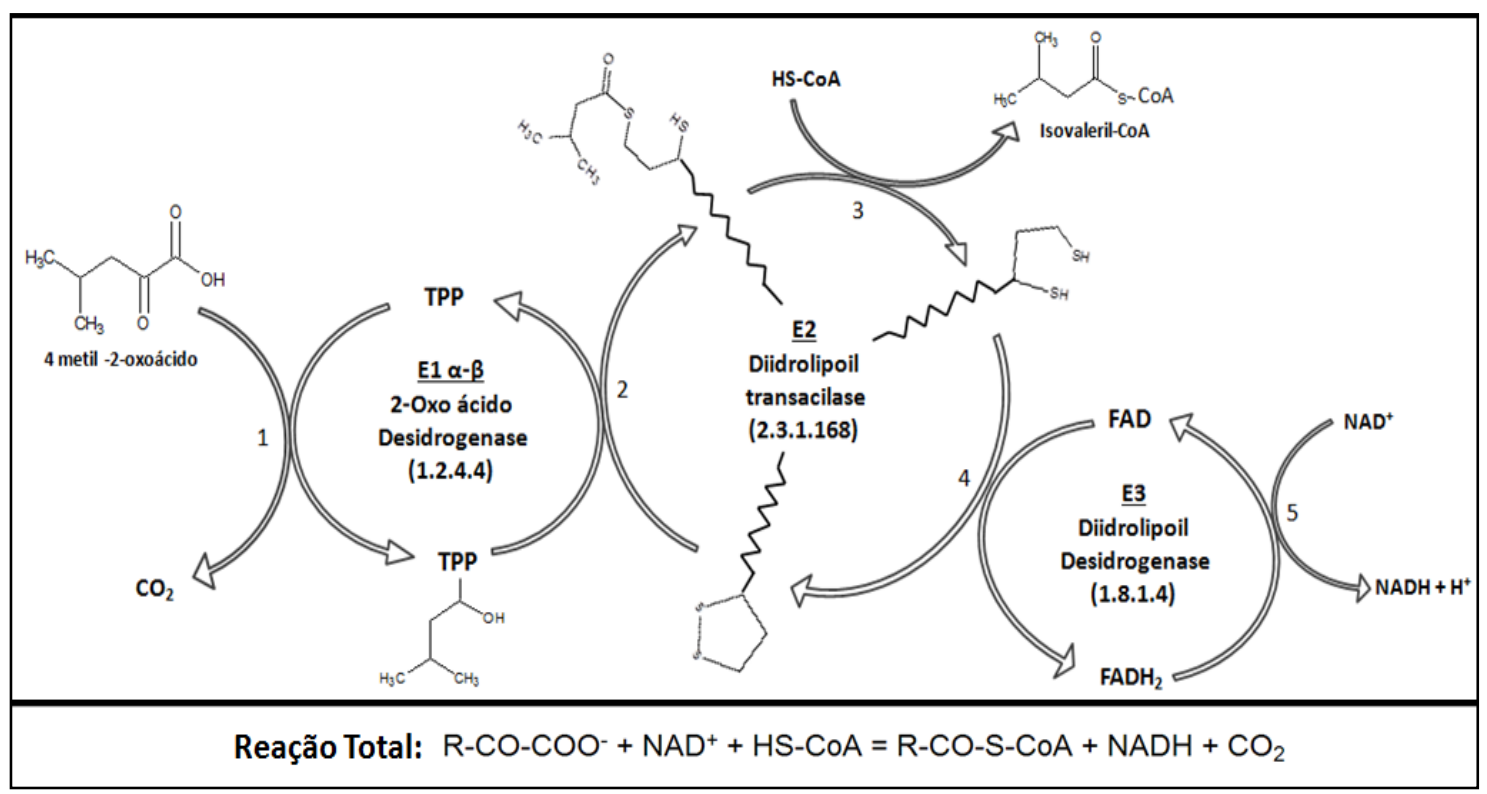

Fonte: Adaptado de REED (2001). E1 (1); E2 (2-3) e E3 (4 e 5).

Depois da descarboxilação oxidativa, a via degradativa dos BCAA diverge em passos catalisados por enzimas distintas para cada aminoácido as quais aportam intermediários ao Ciclo dos Ácidos Tricarboxílicos (TCA). A leucina fornece acetil-CoA e produz $\mathrm{CO}_{2}$. enquanto que isoleucina e valina fornecem carbono para a conversão de propinil-CoA a succinil-CoA (HARPER et al., 1984). O complexo enzimático BCAKDH em humanos está finamente regulado por fosforilação (desativação) e desfosforilação (ativação), isto ocorre no componente enzimático E1 $\alpha$ através de uma enzima qinase e fosfatase específicas de BCAKDH (SHIMOMURA, 2006).

\subsection{Aminoácidos de cadeia ramificada em $T$. cruzi}

O T. cruzi, como a maior parte dos eucariotas não-fotosintéticos, não possui vias de biossíntese para BCAA, consequentemente estes aminoácidos devem ser obtidos do meio extracelular ou pela degradação protéica. Até o começo deste trabalho, não tinha sido descrito nenhum transportador para esses aminoácidos no parasita, mas sabia-se que a leucina marcada radioativamente podia ser incorporada, degradada e produzir $\mathrm{CO}_{2}$ (MANCILLA et al., 1966). Sobre o fornecimento de leucina via degradação protéica, foi descrita uma leucil-peptidase que é majoritariamente expressa nas formas intracelulares (CADAVID-RESTREPO et al., 2011). 
Sobre a degradação dos BCAA, os primeiros estudos em T. cruzi foram desenvolvidos por Blanco e colaboradores que descreveram a atividade de uma "leucina aminotransferase", enzima responsável pelo primeiro passo degradativo dessa via metabólica (MONTAMAT et al., 1987). Anos depois, com o desenvolvimento do projeto genoma do T. cruzi, chamou a atenção a ausência de fases abertas de leitura putativas para sequências que codificam uma leucina aminotransferase, como reportado por Montmant e colaboradores em 1987 (BARRY, 2007). Posteriormente, Nowicki e colaboradores (1993) caracterizaram duas aminotransferases, Tirosina amino transferase (TAT) e Aspartato amino transferase (ASAT), as quais apresentam um espectro de substratos inusualmente amplo, realizando com diferentes eficiências catalíticas as reações de transaminação de diversos aminoácidos incluindo o ácido4-metil-2-oxopentanoico. (NOWICKI et al., 2001a). Porém, até o momento não tinham sido identificadas molecularmente as enzimas que fazem parte da via oxidativa dos BCAA, embora as sequências putativas para a maior parte delas estejam anotadas no genoma do $T$. cruzi (dados do site KEGG pathway).

Vários estudos tem demonstrado que a Pro, promove a diferenciação, tanto nas formas presentes no inseto (CONTRERAS et al., 1985), quanto no ciclo intracelular (TONELLI et al., 2004). Porém, sabe-se muito pouco sobre o papel biológico dos BCAA ao longo do ciclo de vida do parasita. Homsy e colaboradores relataram que leucina e isoleucina podem inibir a metaciclogênese induzida por prolina (HOMSY, J. et al., 1989). Esses autores atribuíram essa atividade inibitória à possível capacidade desses aminoácidos de inibir o segundo passo da via de oxidação da prolina, catalisado pela D1-pirrolina-5-carboxilato desidrogenase, enzima chave no processo de invasão celular e na manutenção da atividade mitocôndrial em situações de estresse nutricional (MANTILLA et al., 2015). Interessantemente, embora a informação sobre essa possível inibição seja relevante para compreender a regulação metabólica da metaciclogênese, permaneceu na literatura de forma especulativa até o presente. Outros possíveis papeis dos BCAA devem também ser mencionados. Foi relatado por exemplo que o parasita pode usar os esqueletos carbonados derivados de Leu na síntese de esteróis ou isoprenóis, esta habilidade conferiría uma vantagem na economia energética ao longo do ciclo (GINGER, et al., 2000). Contudo, não há estudos que descrevam a importância biológica dos BCAA no T. cruzi nem as características bioquímicas das enzimas do seu metabolismo que poderiam estar regulando os níveis de BCAA e, portanto, participando do seu papel regulatório nos processos biológicos dos quais participam. 


\section{CONCLUSÕES}

a) Os BCAA influencíam negativamente os processos de metaciclogênese prolinadependente de $T$. cruzi, (passo de forma replicativa não infectiva E, para forma infectiva e não replicativa $\mathrm{M}$ ).

b) Os BCAA também influencíam negativamente no processo de diferenciação do ciclo intracelular, atuando sobre as formas amastigotas e diminuíndo a produção e eclosão de formas $\mathrm{T}$, procedentes de células $\mathrm{CHO}-\mathrm{K}_{1}$ infectadas.

c) A presença extracelular de concentrações maiores de $1 \mathrm{mM}$ de Leu, diminúi as quantidades de $\mathrm{T}$ procedentes de células $\mathrm{CHO}_{1} \mathrm{~K}_{1}$ infectadas em forma dosedependente.

d) Os BCAA são capazes de estender a viabilidade celular das formas E sob estresse metabólico severo.

e) Os BCAA são incorporados em formas E, por um sistema ativo, saturável comúm aos três aminoácidos e específico para eles.

f) Diferentemente de todos os outros organismos estudados até agora, perante a ausência de transaminases de BCAA em T. cruzi, as transaminases citosólicas TcTAT e TcASAT recombinantes, são as que realizam a desaminação reversível dos BCAA.

g) O genôma de T. cruzi apresenta sequências putativas codificantes para todos os compontenes enzimáticos do complexo $B C A K D H$. As sequências de aminoácidos apresentam os dominios proteicos próprios para realizar as reações de decarboxilação oxidativa dos 2-oxoácidos ramificados.

h) O componente enzimático $T c E 1$ apresenta uma localização mitocôndrial em todas as formas do parasita. As subunidades $T c E 1 \beta$ e $T c E 1 \alpha$ co-localizam juntas e com marcadores mitocondriais em formas E de T. cruzi. A subunidade enzimática TcE1ß, é maiormente expressa nas formas E e M do parasita.

Extratos totais do parasita das formas E, apresentam atividade para o complexo $B C A K D H$. As frações proteicas correspondentes à mitocôndria, apresentam a maior porcentagem de atividade $B C A K D H$. O anticorpo anti-TcE1 $\beta$ reconheceu a proteina nas frações mitocondriais do parasita.

i) O complexo pode ser parcialmente reconstituido in vitro a partir dos componentes $T c \mathrm{E} 1 \beta$ e $T c \mathrm{E} 1 \alpha$ expressos em forma recombinante. O componente reconstituido apresentou atividade decarboxilativa, usando ambos os 2-oxoácidos: 3-metil-2oxopentanoico e 3-metil-2-oxobutanoico, gerando $\mathrm{CO}_{2}$. 
j) O componente enzimático E3 apresenta uma associação proteica com a subunidade $T c \mathrm{E} 1 \beta$ recombinante é o componente $T c \mathrm{E} 3 \mathrm{a}$.

k) Os componentes enzimáticos $T c \mathrm{E} 2, T c \mathrm{E} 1 \alpha$ e $T c \mathrm{E} 3 \mathrm{a}$ que fazem parte do complexo $B C A K D H$, foram detectados por espectrometría de massas usando como ísca a subunidade $T c \mathrm{E} 1 \beta$ recombinante. 


\section{REFERÊNCIAS*}

ADL, S. et al. The new higher level classification of eukaryotes with emphasis on the taxonomy of protists. J Eukary microb., v. 52, n. 5, p. 399-451, 2005. ISSN 1066-5234.

AL-MAILEM, D. M.; HOUGH, D. W.; DANSON, M. J. The 2-oxoacid dehydrogenase multienzyme complex of Haloferax volcanii. Extremo., v. 12, n. 1, p. 89-96, Jan 2008. ISSN 1431-0651.

ALMEIDA-DE-FARIA, M.; FREYMÜLLER, E.; COLLI, W. Trypanosoma cruzi: Characterization of an Intracellular Epimastigote-like Form. Exper., 1999.

APT, W.; ZULANTAY, I. [Update on the treatment of Chagas' disease]., v. 139, n. 2, p. 247257, Rev Méd de Chil., 2011. ISSN 0034-9887.

BAKKER, M. B. et al. Compartmentation protects trypanosomes from the dangerous design of glycolysis. vol. 27, no. 5, p. 2087 - 2082. Proc Natl Acad Sci U S A., 2000.

BARISON, M. J. et al. The active transport of histidine and its role in ATP production in Trypanosoma cruzi. p. 0-13, J Bioenerg Biomembr., 2016. ISSN 1573-6881.

BARISON, M. J. et al. Metabolomics profiling reveals a finely tuned, starvation-induced metabolic switch in Trypanosoma cruzi epimastigotes. p. 0-25 J Biol Chem., 2017. ISSN 1083-351X.

BARISON, M. J. Caracterização e avaliação do papel da degradação de histidina na bioenergética de Trypanosoma cruzi. 2015. 153 f. Tese (Doutorado em Parasitologia) - Ins de Ciên Biom., Universidade de São Paulo, São Paulo 2015.

BARRETT, M. et al. Trypanosome glucose transporters. Mol And Biochem Parasi., v. 91, n. 1, p. 195-205, 1998. ISSN 0166-6851.

BARRY, D. Trypanosomes: after the genome. p. xii - 423 Horiz Scient Press., 2007.

BERRIMAN, M. et al. The genome of the African trypanosome Trypanosoma brucei. (New York, N.Y.), v. 309, n. 5733, p. 416-422, Science., 2005. ISSN 0036-8075.

BIFARI, F.; NISOLI, E. Branched-chain amino acids differently modulate catabolic and anabolic states in mammals: a pharmacological point of view. Br J Pharmacol., v. 174, n. 11, p. 1366-1377, 2017. ISSN 1476-5381.

BINDER, S. Branched-Chain Amino Acid Metabolism in Arabidopsis thaliana. Arabido Book., v. 8, p. e0137, 2010. ISSN 1543-8120.

BIXEL, M.; HUTSON, S.; HAMPRECHT, B. Cellular distribution of branched-chain amino acid aminotransferase isoenzymes among rat brain glial cells in culture. The journal of histochemistry and cytochemistry : J of the Histochemi Socie., v. 45, n. 5, p. 685-694, 1997. ISSN 0022-1554.

*De acordo com:

ASSOCIAÇÃO BRASILEIRA DE NORMAS TÉCNICAS. NBR6023: informação e documentação: referências: elaboração. Rio de Janeiro, 2002. 
BLANKENFELDT, W. et al. Crystal structure of Trypanosoma cruzi tyrosine aminotransferase: substrate specificity is influenced by cofactor binding mode. Protein Sci., v. 8, n. 11, p. 2406-2417, Nov 1999. ISSN 0961-8368.

BOUVIER, L. A. et al. Post genomic analysis of permeases from the amino acid/auxin family in protozoan parasites. Biochem Biophys Res Commun., v. 321, n. 3, p. 547-556, Aug 27 2004. ISSN 0006-291X.

BOWMAN, I. B. R.; TOBIE, E. J.; VON BRAND, T. $\mathrm{CO}_{2}$ fixation studies with the culture form of Trypanosoma cruzi. Comparative, v. 9, n. 2, p. 105-114, 6// Biochemi and Physio., 1963.

BRENER, Z. Biology of Trypanosoma cruzi. Ann Rev Of Microb., v. 27, p. 347-382, 1973. ISSN 0066-4227.

BRENER, Z.; CHIARI, E. [Morphological variations observed in different strains of Trypanosoma cruzi]. Rev do Instit de Med Trop de São Paulo., v. 5, p. 220-224, 1963. ISSN 0036-4665.

BRINGAUD, F.; RIVIÈRE, L.; COUSTOU, V. Energy metabolism of trypanosomatids: adaptation to available carbon sources. Mol And Biochem Parasit., v. 149, n. 1, p. 1-9, 2006. ISSN 0166-6851.

BROSNAN, J.; BROSNAN, M. Branched-chain amino acids: enzyme and substrate regulation. J of Nutri., vol. 136 no. 1, p. 207S-211S, 2006. ISSN 0022-3166.

BURLEIGH, BOOTHROYD (2016). "Editorial overview: Host-microbe interactions: parasites: How eukaryotic parasites meet the challenges of life in a host." Cur Op in Microbiol 32:p. viii-xi.

CADAVID-RESTREPO, G. et al. The major leucyl aminopeptidase of Trypanosoma cruzi (LAPTc) assembles into a homohexamer and belongs to the M17 family of metallopeptidases. BMC bioche., v. 12, p. 46, 2011. ISSN 1471-2091.

CAMARGO, E. P. Growth And Differentiation In Trypanosoma cruzi. I. Origin Of Metacyclic Trypanosomes In Liquid Media. Rev do Inst de Med Trop de São Paulo., v. 6, p. 93-100, 1964. ISSN 0036-4665.

CAMERON, P. et al. Branched-chain amino acids. J of Gastroent and Hepat., v. 15, 2000. ISSN 0815-9319. Vol. 15, Issue 7, 2000, p. 706-717.

CANEPA, G. et al. Characterization of Trypanosoma cruzi L-cysteine transport mechanisms and their adaptive regulation. FEMS Microb Lett., v. 292, n. 1, p. 27-32, 2009. ISSN 03781097.

CANEPA, G. et al. Aspartate transport and metabolism in the protozoan parasite Trypanosoma cruzi. FEMS Microb Lett., v. 247, n. 1, p. 65-71, 2005. ISSN 0378-1097.

CANEPA, G. et al. Biochemical characterization of a low-affinity arginine permease from the parasite Trypanosoma cruzi. FEMS microb letters., v. 236, n. 1, p. 79-84, 2004. ISSN 0378-1097.

CANNATA, J.; CAZZULO, J. The aerobic fermentation of glucose by Trypanosoma cruzi. Comparative biochemistry and physiology. B, Comparat Biochem., v. 79, n. 3, p. 297-308, 1984. 
CAROTHERS, D. J.; PONS, G.; PATEL, M. S. Dihydrolipoamide dehydrogenase: functional similarities and divergent evolution of the pyridine nucleotide-disulfide oxidoreductases. Arch Biochem Biophys., v. 268, n. 2, p. 409-425, Feb 011989.

CARRILLO, C. et al. Molecular and functional characterization of a spermidine transporter (TcPAT12) from Trypanosoma cruzi. Biochem And Biophy Resea Communi., v. 344, n. 3, p. 936-940, 2006. ISSN 0006-291X.

CARRILlO, C. et al. Trypanosoma cruzi amino acid transporter TcAAAP411 mediates arginine uptake in yeasts. FEMS Microbio Letters., v. 306, n. 2, p. 97-102, 2010. ISSN 0378-1097.

CATALA, S.; BEZERRA, C. M.; DIOTAIUTI, L. Thermal preferences and limits of Triatoma brasiliensis in its natural environment--field observations while host searching. Mem Inst Oswaldo Cruz., v. 110, n. 6, p. 793-796, Sep 2015. ISSN 1678-8060.

CAZZULO et al. On the production of glycerol and l-alanine during the aerobic fermentation of glucose by trypanosomatids. FEMS Microbio Lett., v. 51, p. 187 - 191.11988. ISSN 0378-1097.

CAZZULO, J.; STOKA, V.; TURK, V. Cruzipain, the major cysteine proteinase from the protozoan parasite Trypanosoma cruzi. Biolog Chem., v. 378, n. 1, p. 1-10, 1997. ISSN 1431-6730.

CAZZULO, J. J. Aerobic fermentation of glucose by trypanosomatids. FASEB J., v. 6, n. 13, p. 3153-3161, Oct 1992. ISSN 0892-6638.

Intermediate metabolism in Trypanosoma cruzi. J Bioenerg Biomembr., v. 26, n. 2, p. 157-165, Apr 1994. ISSN 0145-479X.

CHAGAS. Nova tripanozomiase humana. Estudos sobre a morfología e o ciclo evolutivo do Schizotrypanum cruzi, agente etiológico de nova entidade mórbida do homen. Mem do Inst Osw Cruz., v. 1, p. 159, 1909.

CHENG, Y.; PRUSOFF, W. H. Relationship between the inhibition constant (K1) and the concentration of inhibitor which causes 50 per cent inhibition (I50) of an enzymatic reaction. Biochem Pharmacol., v. 22, n. 23, p. 3099-3108, 1973.

CHOU, P. Y.; FASMAN, G. D. Structural and functional role of leucine residues in proteins. J Mol Biol., v. 74, n. 3, p. 263-281, 1973. ISSN 0022-2836.

CLAROS, M. G.; VINCENS, P. Computational method to predict mitochondrially imported proteins and their targeting sequences. Eur J Biochem., v. 241, n. 3, p. 779-786, 1996. ISSN 0014-2956.

CONTRERAS, V. et al. In vitro differentiation of Trypanosoma cruzi under chemically defined conditions. Mol and Biochem Parasito., v. 16, n. 3, p. 315-327, 1985. ISSN 01666851.

COURA, J. Present situation and new strategies for Chagas disease chemotherapy: a proposal. Mem do Inst Osw Cruz., v. 104, n. 4, p. 549-554, 2009. ISSN 0074-0276.

Chagas disease: control, elimination and eradication. Is it possible? Mem do Inst Osw Cruz., v. 108, n. 8, p. 962-967, 2013. ISSN 0074-0276.

DE GODOY, L. M. et al. Quantitative proteomics of Trypanosoma cruzi during metacyclogenesis. Proteom., v. 12, n. 17, p. 2694-2703, Aug 2012. ISSN 1615-9861. 
DE MACEDO, J. P. et al. An Atypical Mitochondrial Carrier That Mediates Drug Action in Trypanosoma brucei. PLoS Pathog., v. 11, n. 5, p. e1004875, 2015. ISSN 1553-7374.

DE SOUZA, W. Basic cell biology of Trypanosoma cruzi. Current pharma design., v. 8, n. 4, p. 269-285, 2002. ISSN 1381-6128.

DOCAMPO, R.; MORENO, S. Free radical metabolism of antiparasitic agents. Federa Proceed., v. 45, n. 10, p. 2471-2476, 1986. ISSN 0014-9446.

Acidocalcisome: A novel $\mathrm{Ca} 2+$ storage compartment in trypanosomatids and apicomplexan parasites. Parasit Today (Personal ed.)., v. 15, n. 11, p. 443-448, 1999. ISSN 0169-4758.

The acidocalcisome. Mol and Biochem Parasit., v. 114, n. 2, p. 151-159, 2001. ISSN 0166-6851.

DUSCHAK, V. G.; CAZZULO, J. J. Subcellular localization of glutamate dehydrogenases and alanine aminotransferase in epimastigotes of Trypanosoma cruzi. FEMS Microbiol Lett, v. 67, n. 2, p. 131-135, Oct 01 1991. ISSN 0378-1097.

FIGUEIREDO, R. et al. Reservosome: an endocytic compartment in epimastigote forms of the protozoan Trypanosoma cruzi (Kinetoplastida: Trypanosomatidae). Correlation between endocytosis of nutrients and cell differentiation. Parasitol, v. 129, n. Pt 4, p. 431-438, 2004. ISSN 0031-1820.

FRANKE DE CAZZULO, B. et al. Effects of proteinase inhibitors on the growth and differentiation of Trypanosoma cruzi. FEMS Microbiol lett., v. 124, n. 1, p. 81-86, 1994. ISSN 0378-1097.

GALVEZ ROJAS, R. et al. The Uptake of GABA in Trypanosoma cruzi. J Eukary microb., 2015. p. 1066-5234.

GATTUSO, J.; KAMM, M. Review article: the management of constipation in adults. Alimen pharmacol \& therap., v. 7, n. 5, p. 487-500, 1993. ISSN 0269-2813.

GHISLA, S.; THORPE, C. Acyl-CoA dehydrogenases. A mechanistic overview. Eur J Biochem., v. 271, n. 3, p. 494-508, Feb 2004. ISSN 0014-2956.

GINGER, M. et al. Utilization of leucine and acetate as carbon sources for sterol and fatty acid biosynthesis by Old and New World Leishmania species, Endotrypanum monterogeii and Trypanosoma cruzi. Euro J of Biochem / FEBS., v. 267, n. 9, p. 2555-2566, 2000. ISSN 0014-2956.

GINGER, M. L. et al. The biosynthetic incorporation of the intact leucine skeleton into sterol by the trypanosomatid Leishmania mexicana. J Biol Chem., v. 276, n. 15, p. 11674-11682, Apr 13 2001. ISSN 0021-9258.

GINGER, M. L. et al. Utilization of leucine and acetate as carbon sources for sterol and fatty acid biosynthesis by Old and New World Leishmania species, Endotrypanum monterogeii and Trypanosoma cruzi. Eur J Biochem., v. 267, n. 9, p. 2555-2566, 2000. ISSN 0014-2956.

GOUY, M.; GUINDON, S.; GASCUEL, O. SeaView version 4: A multiplatform graphical user interface for sequence alignment and phylogenetic tree building. Mol Biol Evol., v. 27, n. 2, p. 221-224, Feb 2010. ISSN 1537-1719. 
GRACA-SOUZA, A. V. et al. Adaptations against heme toxicity in blood-feeding arthropods. Insect Biochem Mol Biol., v. 36, n. 4, p. 322-335, Apr 2006. ISSN 0965-1748.

GUALDRÓN-LÓPEZ, M. et al. When, how and why glycolysis became compartmentalised in the Kinetoplastea. A new look at an ancient organelle. Inter J For Parasitol., v. 42, n. 1, p. 1-20, 2012. ISSN 0020-7519.

HAMPTON, J. Lysine uptake in cultured Trypanosoma cruzi: interactions of competitive inhibitors. J of protozool., v. 17, n. 4, p. 597-600, 1970. ISSN 0022-3921.

HANNA, S. L. et al. Comparison of proteins expressed by Pseudomonas aeruginosa strains representing initial and chronic isolates from a cystic fibrosis patient: an analysis by 2-D gel electrophoresis and capillary column liquid chromatography-tandem mass spectrometry. Microbiol., v. 146 ( Pt 10), p. 2495-2508, Oct 2000. ISSN 1350-0872

HANNAERT, V.; OPPERDOES, F. R.; MICHELS, P. A. Glycosomal glyceraldehyde-3phosphate dehydrogenase of Trypanosoma brucei and Trypanosoma cruzi: expression in Escherichia coli, purification, and characterization of the enzymes. Protein Expr Purif., v. 6, n. 3, p. 244-250, Jun 1995. ISSN 1046-5928.

HARINGTON, J. S. Studies of the amino acids of Rhodnius prolixus II. Analysis of the excretory material. Parasitol, v. 51, p. 319-326, Nov 1961. ISSN 0031-1820.

HARPER, A.; MILLER, R.; BLOCK, K. Branched-chain amino acid metabolism. Ann Rev Of Nutrition., p. 409 - 443. 1984.

HENRIQUEZ, D. A. et al. Mechanisms of protein degradation in Trypanosoma cruzi. Biol Res. v. 26, n. 1-2, p. 151-157, 1993. ISSN 0716-9760.

HOCHULI, E.; DOBELI, H.; SCHACHER, A. New metal chelate adsorbent selective for proteins and peptides containing neighbouring histidine residues. J Chromatogr., v. 411, p. 177-184, Dec 181987.

HOMSY, J.; GRANGER, B.; KRASSNER, S. Some factors inducing formation of metacyclic stages of Trypanosoma cruzi. J of protozool., v. 36, n. 2, p. 150-153, 1989. ISSN 00223921.

HOMSY, J. J.; GRANGER, B.; KRASSNER, S. M. Some factors inducing formation of metacyclic stages of Trypanosoma cruzi. J Protozool., v. 36, n. 2, p. 150-153, Mar-Apr 1989. ISSN 0022-3921.

HOTEZ, P. et al. Control of neglected tropical diseases. New Engl J of med., v. 357, n. 10, p. 1018-1027, 2007. ISSN 0028-4793.

HUTSON, S. Structure and function of branched chain aminotransferases. Prog Nucleic Acid Res Mol Biol., v. 70, p. 175-206, 2001. ISSN 0079-6603.

INBAR, E. et al. Lysine transporters in human trypanosomatid pathogens. Amino acids., v. 42, n. 1, p. 347-360, 2012. ISSN 0939-4451.

JACKSON, A. P. Origins of amino acid transporter loci in trypanosomatid parasites. BMC Evol Biol., v. 7, p. 26, Feb 23 2007. ISSN 1471-2148.

JUAN, S. M.; CAZZULO, J. J.; SEGURA, E. L. The citrate synthase from Trypanosoma cruzi. J Parasitol., v. 63, n. 5, p. 921-922, Oct 1977. ISSN 0022-3395. 
KAMERLIN, S. C.; WARSHEL, A. On the energetics of ATP hydrolysis in solution. J Phys Chem B., v. 113, n. 47, p. 15692-15698, Nov 26 2009. ISSN 1520-5207.

KOLliEN, A. H.; SCHAUB, G. A. The development of Trypanosoma cruzi in triatominae. Parasitol Today., v. 16, n. 9, p. 381-387, 2000. ISSN 0169-4758.

KURPAD, A.; REGAN, M.; RAJ, T. Branched-chain amino acid requirements in healthy adult human subjects. J of Nutrition., vol. 136 no. p. 256S-263S;2006.

LARA, F. A. et al. Heme requirement and intracellular trafficking in Trypanosoma cruzi epimastigotes. Biochem Biophys Res Commun., v. 355, n. 1, p. 16-22, 2007. ISSN 0006$291 X$.

LIM, C. L.; BYRNE, C.; LEE, J. K. Human thermoregulation and measurement of body temperature in exercise and clinical settings. Ann Acad Med Singapore., v. 37, n. 4, p. 347353, 2008. ISSN 0304-4602.

LIU, B. et al. Trypanosomes have six mitochondrial DNA helicases with one controlling kinetoplast maxicircle replication. Mol Cell., v. 35, n. 4, p. 490-501, 2009. ISSN 1097-2765.

LUNDGREN, D. W.; OGUR, M. Inhibition of yeast 1 -pyrroline-5-carboxylate dehydrogenase by common amino acids and the regulation of proline catabolism. Biochim Biophys Acta., v. 297, n. 2, p. 246-257, 1973. ISSN 0006-3002.

MACHIUS, M. et al. A versatile conformational switch regulates reactivity in human branched-chain alpha-ketoacid dehydrogenase. Structure, v. 14, n. 2, p. 287-298, 2006. ISSN 0969-2126.

MAGDALENO A, AHN I-Y, PAES L. S., SILBER A. M. Actions of a Proline Analogue, LThiazolidine-4-Carboxylic Acid (T4C), on Trypanosoma cruzi. Plos One 4(2): e4534 p. 0 10. 2009. doi:10.1371/journal.pone.000453

MANCHOLA, N. C. et al. Biochemical Characterization of Branched Chain Amino Acids Uptake in Trypanosoma cruzi. J Eukary microb., p. 299-308; 2015. ISSN 1066-5234. Disponível em: < http://dx.doi.org/10.1111/jeu.12278 >.

MANCILLA, R.; NÁQUIRA, C.; LANAS, C. Protein biosynthesis in Trypanosomidae. I. In vivo incorporation of leucine-C14 in Trypanosoma cruzi. Comp Biochem and Physiol., v. 18, n. 2, p. 241-248, 1966. ISSN 0010-406X.

MANTILLA, B. S. et al. Role of Delta1-Pyrroline-5-Carboxylate Dehydrogenase Supports Mitochondrial Metabolism and Host-Cell Invasion of Trypanosoma cruzi. J Biol Chem., v. 290, n. 12, p. 7767-7790, Mar 20 2015. ISSN 1083-351X.

MARCIANO, D. et al. Biochemical characterization of stage-specific isoforms of aspartate aminotransferases from Trypanosoma cruzi and Trypanosoma brucei. Mol and Biochem Parasitol., v. 161, n. 1, p. 12-20, 2008. ISSN 0166-6851.

MARSHALL, N. J.; GOODWIN, C. J.; HOLT, S. J. A critical assessment of the use of microculture tetrazolium assays to measure cell growth and function. Growth Regul., v. 5, n. 2, p. 69-84, Jun 1995. ISSN 0956-523X.

MARTINS, R. M., COVARRUBIAS, C., ROJAS, R. G., SILBER, A. M., \& YOSHIDA, N. (2009). Use of 1-Proline and ATP Production by Trypanosoma cruzi Metacyclic Forms as Requirements for Host Cell Invasion . Infec and Immun., 77(7), p. 3023-3032. http://doi.org/10.1128/IAI.00138-09 
MATSUDA, N.; MILLER, S.; EVORA, P. The chronic gastrointestinal manifestations of Chagas disease. Clinics (São Paulo, Brazil)., v. 64, n. 12, p. 1219-1224, 2009. ISSN $1807-$ 5932.

MCMILLAN, P. J. et al. The human malaria parasite Plasmodium falciparum possesses two distinct dihydrolipoamide dehydrogenases. Mol Microbiol., v. 55, n. 1, p. 27-38, Jan 2005. ISSN 0950-382X.

MICHELS, P. et al. Metabolic functions of glycosomes in trypanosomatids. Biochem Biophy Acta., v. 1763, n. 12, p. 1463-1477, 2006. ISSN 0006-3002.

MONCAYO, A.; ORTIZ YANINE, M. I. An update on Chagas disease (human American trypanosomiasis). Ann Trop Med Parasitol., v. 100, n. 8, p. 663-677, 2006. ISSN 00034983.

MONTAMAT, E.; ARAUZO, S.; BLANCO, A. Subcellular localization of leucine aminotransferase and alpha-hydroxyacid dehydrogenase in Trypanosoma cruzi. Mol Biochem Parasitol., v. 22, n. 2-3, p. 185-193, 1987. ISSN 0166-6851.

MULLER, Y. A. et al. A thiamin diphosphate binding fold revealed by comparison of the crystal structures of transketolase, pyruvate oxidase and pyruvate decarboxylase. Structure., v. 1, n. 2, p. 95-103, Oct 15 1993. ISSN 0969-2126.

NOGUEIRA, N. P. et al. Proliferation and differentiation of Trypanosoma cruzi inside its vector have a new trigger: redox status. PLoS One., v. 10, n. 2, p. e0116712, 2015. ISSN 1932-6203.

NORMAN, F. F.; LÓPEZ-VÉLEZ, R. Mother-to-child transmission of Trypanosoma cruzi infection (Chagas disease): a neglected problem. Transac Royal Society of Trop Med Hyg., 2014. ISSN 0035-9203.

NOWICKI, C.; CAZZULO, J. Aromatic amino acid catabolism in trypanosomatids. Comp Biochem Physiol A Mol Integr Physiol., v. 151, n. 3, p. 381-390, 2008. ISSN 1095-6433.

NOWICKI, C.; CAZZULO, J. J. Aromatic amino acid catabolism in trypanosomatids. Comp Biochem Physiol A Mol Integr Physiol., v. 151, n. 3, p. 381-90, Nov 2008. ISSN 15314332 .

NOWICKI, C. et al. Recombinant tyrosine aminotransferase from Trypanosoma cruzi: structural characterization and site directed mutagenesis of a broad substrate specificity enzyme. Biochem Biophy Acta., v. 1546, n. 2, p. 268-281, 2001a. ISSN 0006-3002.

NOWICKI, C. et al. Recombinant tyrosine aminotransferase from Trypanosoma cruzi: structural characterization and site directed mutagenesis of a broad substrate specificity enzyme. Biochim Biophys Acta., v. 1546, n. 2, p. 268-281, Apr 7 2001b. ISSN 0006-3002.

OGBADOYI, E.; ROBINSON, D.; GULL, K. A high-order trans-membrane structural linkage is responsible for mitochondrial genome positioning and segregation by flagellar basal bodies in trypanosomes. Mol Biol Cell., v. 14, n. 5, p. 1769-1779, 2003. ISSN 1059-1524.

OPPERDOES, F.; BORST, P. Localization of nine glycolytic enzymes in a microbody like organelle in Trypanosoma brucei: The glycosome. FEBS lett., v. 80, n. 2, p. 360-364, 1977.

OSUNA, A.; ADROHER, F. J.; LUPIANEZ, J. A. Influence of electrolytes and nonelectrolytes on growth and differentiation of Trypanosoma cruzi. Cell Differ Dev., v. 30, n. 2, p. 89-95, May 1990. ISSN 0922-3371. 
PACKCHANIAN, A. Chemotherapy of experimental Chagas' disease with nitrofuran compounds. Antibio \& Chemothera., v. 7, n. 1, p. 13-23, 1957. ISSN 0570-3123.

PAES, L. et al. The Uniqueness of the Trypanosoma cruzi Mitochondrion: Opportunities to Target New Drugs Against Chagas Disease. Curr Pharmace Design., v. 17, n. 20, p. 20742099, 2011. ISSN 13816128.

PAES, L. S. et al. Proline dehydrogenase regulates redox state and respiratory metabolism in Trypanosoma cruzi. PLoS One., v. 8, n. 7, p. e69419, 2013. ISSN 1932-6203

PARKER, E.; SETHI, A. CHAGAS disease: coming to a place near you. Dermatol Clinics., v. 29, n. 1, p. 53-62, 2011. ISSN 0733-8635.

PEREIRA, C. et al. L-arginine uptake and L-phosphoarginine synthesis in Trypanosoma cruzi. J Eukary microb., v. 46, n. 6, p. 566-570, 1999. ISSN 1066-5234.

PEREIRA, C. et al. [Trypanosoma cruzi: transport of essential metabolites acquired from the host]. Med., v. 68, n. 5, p. 398-404, 2008. ISSN 0025-7680.

PEREZ, C. J.; LYMBERY, A. J.; THOMPSON, R. C. Reactivation of Chagas Disease: Implications for Global Health. Tre In Parasitol., v. 31, n. 11, p. 595-603, 2015. ISSN 14714922.

PERHAM, R. Domains, motifs, and linkers in 2-oxo acid dehydrogenase multienzyme complexes: a paradigm in the design of a multifunctional protein. Biochem., 30 (35), p. 85018512. 1991.

PERHAM, R.; PACKMAN, L. 2-Oxo Acid Dehydrogenase Multienzyme Complexes: Domains, Dynamics, and Design. Ann New York Acad., 1989. vol 573, p. 1-20.

PINTO DIAS, J. The treatment of Chagas disease (South American trypanosomiasis). Ann of Internal Med., v. 144, n. 10, p. 772-774, 2006. ISSN 0003-4819.

POHL, B.; RAICHLE, T.; GHISLA, S. Studies on the reaction mechanism of general acylCoA dehydrogenase. Determination of selective isotope effects in the dehydrogenation of butyryl-CoA. Eur J Biochem., v. 160, n. 1, p. 109-115, Oct 01 1986. ISSN 0014-2956.

POLAK, A.; RICHLE, R. Mode of action of the 2-nitroimidazole derivative benznidazole. Ann Trop Med Parasitol., v. 72, n. 1, p. 45-54, 1978. ISSN 0003-4983.

PUIG, O. et al. The tandem affinity purification (TAP) method: a general procedure of protein complex purification. Methods., v. 24, n. 3, p. 218-229, 2001. ISSN 1046-2023.

PUNUKOLLU, G. et al. Clinical aspects of the Chagas' heart disease. J Cardiol., v. 115, n. 3, p. 279-283, 2007. ISSN 0167-5273.

RACAGNI, G. E.; MACHADO DE DOMENECH, E. E. Characterization of Trypanosoma cruzi hexokinase. Mol Biochem Parasitol., v. 9, n. 2, p. 181-188, Oct 1983. ISSN 0166-6851.

RALF, S. et al. Cloning, Sequencing and Functional Expression of Dihydrolipoamide Dehydrogenase from the Human Pathogen Trypanosoma cruzi. Euro J of Biochem., v. 243, 1997. ISSN 0014-2956.

RASSI, A.; RASSI, A.; MARIN-NETO, J. Chagas disease. Lancet, v. 375, n. 9723, p. 13881402, 2010. ISSN 0140-6736. 
REED, L. J. A Trail of Research from Lipoic Acid to -Keto Acid Dehydrogenase Complexes. J of Bio Chem., v. 276, 2001. ISSN 0021-9258.

RIOU, G.; DELAIN, E. Abnormal circular DNA molecules induced by ethidium bromide in the kinetoplast of Trypanosoma cruzi. Proceed Nati Acad of Scienc Unit Stat America., v. 64, n. 2, p. 618-625, 1969. ISSN 0027-8424.

ROBERT, X.; GOUET, P. Deciphering key features in protein structures with the new ENDscript server. Nucleic Acids Res., v. 42, n. Web Server issue, p. W320-4, Jul 2014. ISSN $1362-4962$.

ROHLOFF, P.; MONTALVETTI, A.; DOCAMPO, R. Acidocalcisomes and the contractile vacuole complex are involved in osmoregulation in Trypanosoma cruzi. J Biol Chem., v. 279 , n. 50, p. 52270-52281, 2004. ISSN 0021-9258.

ROLDAN, A. et al. Lipoamide dehydrogenase is essential for both bloodstream and procyclic Trypanosoma brucei. Mol Microbiol., v. 81, n. 3, p. 623-39, Aug 2011. ISSN 13652958.

RYTER, S. W.; TYRRELL, R. M. The heme synthesis and degradation pathways: role in oxidant sensitivity. Heme oxygenase has both pro- and antioxidant properties. Free Radic Biol Med., v. 28, n. 2, p. 289-309, Jan 15 2000. ISSN 0891-5849.

SAIER, M. H., JR. et al. The Transporter Classification Database (TCDB): recent advances. Nucleic Acids Res., v. 44, n. D1, p. D372-9, Jan 04 2016. ISSN 1362-4962.

SANT'ANNA, C. et al. Subcellular proteomics of Trypanosoma cruzi reservosomes. Proteomics., v. 9, n. 7, p. 1782-1794, 2009. ISSN 1615-9853. Disponível em: < http://dx.doi.org/10.1002/pmic.200800730>.

SAYÉ, M. et al. Proline modulates the Trypanosoma cruzi resistance to reactive oxygen species and drugs through a novel D, L-proline transporter. PloS one., v. 9, n. 3, 2014. ISSN 1932-6203. Disponível em: < http://dx.doi.org/10.1371/journal.pone.0092028 >.

SCHONECK, R. et al. Cloning, sequencing and functional expression of dihydrolipoamide dehydrogenase from the human pathogen Trypanosoma cruzi. Eur J Biochem., v. 243, n. 3, p. 739-747, Feb 1 1997. ISSN 0014-2956

SCOTT, D. et al. In situ compositional analysis of acidocalcisomes in Trypanosoma cruzi. $\mathbf{J}$ Biol Chem., v. 272, n. 44, p. 28020-28029, 1997. ISSN 0021-9258. Disponível em: < http://www.ncbi.nlm.nih.gov/pubmed/9346954 >.

SHIMOMURA, Y. et al. Nutraceutical effects of branched-chain amino acids on skeletal muscle. J Nutr., v. 136, n. 2, p. 529S-532S, Feb 2006. ISSN 0022-3166.

SILBER, A. et al. Amino acid metabolic routes in Trypanosoma cruzi: possible therapeutic targets against Chagas' disease. Current drug targets. Infec Disor., v. 5, n. 1, p. 53-64, 2005. ISSN 1568-0053.

SILBER, A. et al. Biochemical characterization of the glutamate transport in Trypanosoma cruzi. Interna J Parasitol., v. 36, n. 2, p. 157-163, 2006. ISSN 0020-7519. Disponível em: < http://dx.doi.org/10.1016/j.ijpara.2005.10.006 >.

SILBER, A. et al. Glucose uptake in the mammalian stages of Trypanosoma cruzi. Mol Biochem Parasitol., v. 168, n. 1, p. 102-108, 2009. ISSN 0166-6851. Disponível em: < http://dx.doi.org/10.1016/j.molbiopara.2009.07.006 >. 
SILBER, A. et al. Active transport of L-proline in Trypanosoma cruzi. J Eukary microb., v. 49, n. 6, p. 441-446, 2002. ISSN 1066-5234. Disponível em: < http://dx.doi.org/10.1111/j.1550-7408.2002.tb00225.x >.

SILBER, A. M. et al. Biochemical characterization of the glutamate transport in Trypanosoma cruzi. Int J Parasitol., v. 36, n. 2, p. 157-163, Feb 2006. ISSN 0020-7519 (Print)

SINGHA, U. K. et al. Characterization of the mitochondrial inner membrane protein translocator Tim17 from Trypanosoma brucei. Mol Biochem Parasitol., v. 159, n. 1, p. 3043, May 2008. ISSN 0166-6851.

SOARES, M. The reservosome of Trypanosoma cruzi epimastigotes: an organelle of the endocytic pathway with a role on metacyclogenesis. Mem Instit Oswaldo Cruz., v. 94 Suppl 1, p. 139-141, 1999. ISSN 0074-0276. Disponível em: < http://www.ncbi.nlm.nih.gov/pubmed/10677701 >.

SOARES, M.; SOUTO-PADRÓN, T.; DE SOUZA, W. Identification of a large prelysosomal compartment in the pathogenic protozoon Trypanosoma cruzi. J Cell Science., v. 102 ( Pt 1), p. 157-167, 1992. ISSN 0021-9533. Disponível em: < http://www.ncbi.nlm.nih.gov/pubmed/1500438 >.

SOUZA, W. Electron microscopy of trypanosomes, a historical view. Mem Instit Oswaldo Cruz., v. 103, n. 4, p. 313-325, 2008. ISSN 0074-0276. Disponível em: < http://dx.doi.org/10.1590/S0074-02762008000400001 >.

STERKEL, M.; OLIVEIRA, P. L. Developmental roles of tyrosine metabolism enzymes in the blood-sucking insect Rhodnius prolixus. Proc Biol Sci., v. 284, n. 1854, May 172017. ISSN 1471-2954.

SULLIVAN, J. J. Metacyclogenesis of Trypanosoma cruzi in vitro: a simplified procedure. Trans R Soc Trop Med Hyg., v. 76, n. 3, p. 300-303, 1982. ISSN 0035-9203.

TEIXEIRA, D. et al. Interactive multimedia to teach the life cycle of Trypanosoma cruzi, the causative agent of Chagas disease. PLoS Neg Trop Disea., v. 6, n. 8, 2012. ISSN 1935-2727. Disponível em: < http://dx.doi.org/10.1371/journal.pntd.0001749>.

TEIXEIRA, M. M.; YOSHIDA, N. Stage-specific surface antigens of metacyclic trypomastigotes of Trypanosoma cruzi identified by monoclonal antibodies. Mol Biochem Parasitol., v. 18, n. 3, p. 271-282, 1986. ISSN 0166-6851. Disponível em: < http://www.ncbi.nlm.nih.gov/pubmed/3515178>.

TETAUD, E. et al. Characterization of glucose transport and cloning of a hexose transporter gene in Trypanosoma cruzi. Proceed Nati Acad of Scienc Unit Stat America., v. 91, n. 17, p. 8278-8282, 1994. ISSN 0027-8424. Disponível em: < http://dx.doi.org/10.1073/pnas.91.17.8278 >.

TONELLI, R. R. et al. L-proline is essential for the intracellular differentiation of Trypanosoma cruzi. Cell Microbiol., v. 6, n. 8, p. 733-741, Aug 2004. ISSN 1462-5814.

TYLER, K.; ENGMAN, D. The life cycle of Trypanosoma cruzi revisited. Interna J Parasitol., v. 31, n. 5-6, p. 472-481, 2001. ISSN 0020-7519. Disponível em: < http://www.ncbi.nlm.nih.gov/pubmed/11334932 >. 
UCROS, H.; GRANGER, B.; KRASSNER, S. M. Trypanosoma cruzi: effect of $\mathrm{pH}$ on in vitro formation of metacyclic trypomastigotes. Acta Trop., v. 40, n. 2, p. 105-112, Jun 1983. ISSN 0001-706X.

URBINA, J. Intermediary metabolism of Trypanosoma cruzi. Parasitol Today (Personal ed.)., v. 10, n. 3, p. 107-110, 1994. ISSN 0169-4758. Disponível em: < http://dx.doi.org/10.1016/0169-4758(94)90010-8 >.

URBINA, J.; CRESPO, A. Regulation of energy metabolism in Trypanosoma (Schizotrypanum) cruzi epimastigotes. I. Hexokinase and phosphofructokinase. Mol Biochem Parasitol., v. 11, p. 225-239, 1984. ISSN 0166-6851. Disponível em: < http://dx.doi.org/10.1016/0166-6851(84)90068-9 >.

URBINA, J. A. Specific chemotherapy of Chagas disease: relevance, current limitations and new approaches. Acta Trop., v. 115, n. 1-2, p. 55-68, Jul-Aug 2010. ISSN 1873-6254 (Electronic)

WHO. Chagas disease (American trypanosomiasis) - fact sheet (revised in August 2012). Relevé épidémiologique hebdomadaire / Section d'hygiène du Secrétariat de la Société des Nations = Weekly epidemiological record / Health Section of the Secretariat of the League of Nations, v. 87, n. 51/52, p. 519-522, 2012. ISSN 0049-8114. Disponível em: < http://www.ncbi.nlm.nih.gov/pubmed/23311009 >.

- Chagas disease (American trypanosomiasis) 2014. Disponível em: < http://www.who.int/mediacentre/factsheets/fs340/en/ >.

YEAMAN, S. The 2-oxo acid dehydrogenase complexes: recent advances. Biochem J., 1989. Disponível em: < http://www.ncbi.nlm.nih.gov/pmc/articles/PMC1135633/ >.

YEAMAN, S. J. The mammalian 2-oxoacid dehydrogenases: a complex family. Trends Biochem Scien., v. 11, 1986. ISSN 0968-0004. Disponível em: < http://dx.doi.org/10.1016/0968-0004(86)90033-2 >.

YOSHIDA, N.; TYLER, K. M.; LLEWELLYN, M. S. Invasion mechanisms among emerging food-borne protozoan parasites. Trends Parasitol., v. 27, n. 10, p. 459-466, Oct 2011. ISSN 1471-5007.

ZELEDON, R. Comparative physiological studies on four species of hemoflagellates in culture. II. Effect of carbohydrates and related substances and some amino compounds on the respiration. J Parasitol., v. 46, p. 541-551, 1960. ISSN 0022-3395.

ZHANG, S. et al. Novel metabolic and physiological functions of branched chain amino acids: a review. J Anim Sci Biotechnol., v. 8, p. 10, 2017. ISSN 1674-9782 (Print) 16749782 (Linking). Disponível em: < http://www.ncbi.nlm.nih.gov/pubmed/28127425 >.

ZINGALES, B. et al. Trypanosoma cruzi genome project: biological characteristics and molecular typing of clone CL Brener. Acta Trop., v. 68, n. 2, p. 159-173, Nov 1997. ISSN 0001-706X (Print) 0001-706X (Linking). Disponível em: < http://www.ncbi.nlm.nih.gov/pubmed/9386791 >. 